\title{
Importance of Dialogue Nature in the Mediator's Competence
}

\author{
Viktorija Portere ${ }^{1}$ Mg. jur.; Baiba Briede ${ }^{2}$ Dr. paed. \\ Latvia University of Life Sciences and Technologies, Faculty of Engineering, \\ Institute of Education and Home Economics, Latvia \\ viktorija.portere@gmail.com¹, baiba.briede@llu.1v²
}

\begin{abstract}
Dialogue skills open opportunities to communicate with people purposefully and help to set out information clearly and completely. Dialogue is the main means for successful communication with clients and it helps to maintain the process of mutual relations. The study relates to descriptions of dialogue and dialogical relations in the works of Eastern and Western scientists from the 19th to the 21st century. The aim of the study is to outline the nature of dialogue and to substantiate and explain its functions, components and barriers essential in a mediation process. The main method of the study was the theoretical analysis of dialogue dealing with its importance in education and democracy, and the nature, components, functions and barriers. Dialogue functions, components and barriers are three groups of factors every person has to consider in the process of mediation. A mediator's task is to explain clients the essence and impact of each factor in the conflict solving process. Therefore, learning to be in dialogical relations should be organised before starting the actual dialogue with other person to solve the conflict.
\end{abstract}

Keywords: dialogue, dialogue barriers, dialogue components, dialogue functions, mediator.

\section{Introduction}

Dialogue arose from the Greek word dialogos and its two parts logos and dia mean through the words pointing to the process when speaking in deep is important to find out new dimensions of understandings and meanings of views and relations. Dialogue as one of the most humanistic means of making relations more positive has justified itself through centuries and nowadays it is a basis in the mediation process as well. Dialogue is one of the features of the mediator's competence and improvement of dialogical skills is a part of the mediator's further education.

As dialogical skills and conclusions on them have been developing through centuries it is possible to find diverse conclusions and explanations in many philosophical, pedagogical, communication, sociological, psychological, biological, philological, art and other scientific works. The vastness and deepness of the dialogue is described by D. Yankelovich (1999) raising a thesis that there is something magic in it transforming a conflict into co-operation. He recognizes that because of this magic capability the dialogue is unique and other ways of communication cannot implement this positive action, and it is a means of resolving disagreements, sharing information as well as improving a personality and worldview.

As dialogical capabilities are so great it is necessary to revise and reassess their opportunities in relation to concrete professional actions and in this concrete case in the context of the mediator's responsibilities. The study is focused on the dialogue components considering the mediator's work peculiarities with a client.

According to Mediation Law Article No.1 of Latvia Republic (Mediation Law, 2014) mediation is a voluntary co-operation process during which the both sides try to get to mutually acceptable agreement for solving their disagreement by means of mediation.

Mediation is a legal process in many countries and duties and restrictions of the mediator are determined. One example is Malta Mediation Centre where the mediator's main actions are explained also in the homepage. The principal role of the mediator is to facilitate communication between the parties in conflict with a view to helping them reach a voluntary resolution to their dispute that is timely, fair and costeffective. Although the mediator manages the meeting and is in charge of the proceedings, he/she should not impose solutions or decisions and has no power to force a settlement. A solution should only be reached by agreement between the parties. They are responsible for the ultimate resolution of the dispute. Furthermore, a mediator has no right or duty to provide legal advice to the parties even if he/she happens to be a lawyer. The parties should seek legal advice solely from their legal counsel. The mediator, however, may raise issues and help parties explore options (Roles and Duties..., 2018). 
Malta Mediation Centre's explanation of the mediator reflects his/her nature and functions and actually they are common in mediation processes in democratic societies. A mediator usually organizes the talks between conflicting sides and act as a guiding force while assisting them to reach a solution. The mediator is not allowed to express personal opinions on the case but he has to promote mutual understanding of both sides by means of dialogue. That is why the aim of the study is to outline the nature of dialogue and to substantiate and explain its functions, components and barriers essential in the mediation process.

\section{Methodology}

In the process of the study the task was to find out theoretical explanations what does it mean to be in a dialogue, what happens within it and what dialogical components, functions and barriers can be summed up. The study relates to descriptions of dialogue and dialogical relations in the works of Eastern and Western scientists from the 19 th to the 21 st century.

The main method of the study was the theoretical analysis of dialogue dealing with its importance in education and democracy, and the nature, components, functions and barriers by M. Bakhtin (1984), D. Bohm (2004), M. Buber (2010), P. Freire (1972), J. Habermas (1984), W. Isaacs (1999) and J. KabatZinn (2006).

\section{Theoretical analysis of dialogue}

Dialogue can be treated as a complicated and difficult form of communication. It belongs to face to face communication covering a variety rules and having an impact on an individual's personal development (Bakhtin, 1984).

Mediation as a process between a mediator and client actually is learning in its own way by means of dialogue. P. Freire's (Freire, 1972) findings on dialogue in relation to people who had been oppressed could be also useful in mediation because dialogue functions as a specific lesson helping to understand that in everybody is a free spirit and we have to treat each other as subjects and promote respect towards each other. P. Freire (1972) stresses the dialogue's cultural and co-operative function and this is one more good reason why a mediator has to be conscious of the dialogue's positive impact on clients' relations.

J. Jermolajeva's (Jermolajeva, 1997) conclusions are close to P. Freire's (Freire, 1972) opinions on dialogical nature and functions. Her studies reveal that the goal of dialogical upbringing should be the development of dialogical personality who is conscious on connection with the world and people around us, positive in dialogical situations, active, capable to reflect and think rationally. Reaching or coming closer to the goal is a big success for every person because this process creates humanistic transformations and positive experience. The role of the teacher is crucial in the process of learning to become a dialogical personality. V. Purens (2012) named the following qualities of dialogically open teacher: belief and respect of the student; readiness to listen to; readiness to be helpful in difficult situations; ability to find balance between authority and the student's wish for creative expression; flexible manoeuvring with assessment and discussions promoting students' openness for a dialogue. The teacher's qualities and the students' benefits of becoming dialogical personalities reveal a wide range of the opportunities of the dialogue and understanding difficulties and advantages of the process of learning to keep dialogical relations. This is a complicated and time-consuming process. That is why every mediator has to manage dialogical theories and relations with the purpose to teach them to their clients and dialogical themes should take a crucial part of the further education programme of mediators.

According to M. Bakhtin (1984) the development of the dialogical paradigm became more stable in the $20^{\text {th }}$ century and before it in the culture of new ages the monologic paradigm was a dominating one. M. Bakhtin (1984) states that all human actions can be divided into ritual and responsible ones. The ritual actions are focused on the performance of the concrete role to be involved in the appropriate socium or excluded from it if the role is not played according to the standards of each socium. At the same time each real action forms a new event and a person to some extent deviate from a ritual. It is necessary to consider the ritual aspect in the process of the dialogue and understand individually conscious actions influencing a ritual as factors typical to human behaviour. The idea of ritual actions can be complemented with M Buber's (2010) statements that a man who confronts another man can create three pictures: 1) the way he wants to present himself, 2) the way he actually presents himself and 3 ) what he is really like. The areas marked by the relation „,between"e can be described as: a mutuality area - „being " with other person, confronting someone or something, a contrast area - for and against, 
which may assume the form of rivalry and power area which includes the moment of fight. Dialogue relation is when we speak in level I-You and monologue relation is when we speak in level I-It.

M. Buber (2010) wrote about three types of dialogues: monologue disguised as a dialogue, technical dialogue which concerns substantial understanding and real dialogue if we embrace the other or others in their existence. A deep dialogue in the sense of lack of effect is possible only in the situation of mutuality, when both parties perceive each other as supporters, at that moment, of dialogue which is supposed not to have any aim.

M. Bakhtin (1984) recognises that a dialogue is a universal way of human existence. This idea is reflected in the $20^{\text {th }}$ and $21^{\text {st }}$ century efforts to keep sustainable development model of society which is based on the principle of harmony between the society and nature, cultural and civilisation processes emphasising dialogical interaction. The efforts, for example, result in peak meetings such as annual World Economic Forum where topical problems of the world are discussed by prominent experts and reports with suggestions are published to pay governments' attention to urgent problems and highlight the importance of their solution (Reports, 2019). It also means the development of multisided skills: listening and hearing, ability to trust the world and other people, to feel connection with the surrounding world, responding to a dialogical situation, deep feeling of one's own "Me", development of high level of rational thinking, development of high level of reflection, autonomous ability of individual behaviour, ability to develop one's individual position and also doubt it, be able to change one's personality, be able to recognise own lack of knowledge or weakness, be able to ask for help from other person and receive it.

Making a dialogue is also quite rational and even technical process because there is an exchange of information and it relates to communication rules. According to N. Luman (1995) there are several types of interrelated selections in communication. They are selection of: understanding and misunderstanding, nature of information and giving of information. N. Luman's thesis is only one example of quite a lot of challenges an individual meet in the complicated communication process. It means that dialogical skills also comprise understanding of communication rules and models.

According to M. Bakhtin (1984) and E. Levinas (Stanford Encyclopedia of Philosophy..., 2006) a relevant feature of dialogue is uniqueness/otherness/tolerance of partners and their positions.

Other dialogue features according to M. Bakhtin (1984) are the following: positions in border area when is a possibility to change; the presence of non-alibi - action in a position of concerned interest, crossexamination; a monologue as a finished sentence and rejoinder from all the dialogue; trust in other words; readiness to learn and explore; search and need to deeper meaning; acceptance; putting the meaning on the point and slouching of meanings; understanding, complementary understanding and understanding beyond borders (understanding how present, understanding of past contexts and expected understanding); the understanding of partner's language and statements; responsibility for statements, words and emotions; logic.

The peculiarity of the method of dialogue is making equal relations among all sides with the purpose to investigate a situation deeply and find a solution together. This method promotes the development of all sides involved in the dialogue. The effectiveness of the mediator's activities depends on competence and in the context of client situations including also personal qualities. The mediators have to try to create a positive social environment and the method of dialogues serves as a link of finding common points for the conflicting sides. The effectiveness of the mediator's competence expresses particularly in conflict and unknown situations, and positive solution depends on the mediator's ability to keep dialogue and achieve mutual understanding among conflicting sides.

D. Bohm (2004) stresses that in a dialogue everybody is a winner. He stresses also physical part in the dialogue calling that mental and physical and there is a close relation between them through information. D. Bohm (2004) perceives the dialogue as a means of filling in a room with maximal attention allowing each person to express oneself both verbally and non-verbally. He recognises reflective function of the dialogue and compares it with a flow of meanings which goes around and through people as well as the function of making culture of mutual understanding, development of thinking and equality excluding hierarchical relations.

D. Bohm (2004) recognises the necessity of help to begin a dialogue and here he speaks about the third person's role who functions as a promoter who acts quite discreetly. It is worth mentioning Bohm's 
conclusion that participants in a group dialogue overcome fragmentarism and isolation together in spite of their different backgrounds. He calls it a true dialogue where people open their views, assumptions and judgements. D. Bohm's (Bohm, 2004) ideas about collectivistic effect of the dialogue are in harmony with W. Isaacs (1999) findings that dialogue keeps people together and they do not keep only to one position but think together and look for possibilities. He also stresses that the dialogue generates respect towards each other as well as fresh ideas. W. Isaacs (1999) and J. Kabat-Zinn (2006) state that the dialogue also is an essential means of developing intelligentsia in every person.

J. Habermas (1984) describing dialogical situation stressed the importance of critical dialogue in which such qualities as bilateral relations without prejudices, free of domination. J. Habermas (1984) stressed that sophisticated skills of introspection, curiosity of otherness and a willingness to uphold reason over power are required in dialogue.

A mediator's role is not only to promote a dialogue but also to keep its humanistic bilateral culture where the border between the dialogue and not hearing a partner is quite fragile. Efforts are necessary to be in a dialogue and defend one's views and truths and here the mediator's role is very important because he/she helps to get a solution of the problem from one side and to foster the development of more intelligent personality able to hear others and keep the dialogue from other side.

Every mediator has to understand not only positive but also a barrier or negative side in a mediation process as well as that an attempt at dialogue can be very frustrating and could be long process of learning for both conflicting sides.

\section{Results and Discussion}

Considering theoretical investigations of dialogue, it is possible to determine the following components:

- genuineness;

- emphatic understanding;

- active listening;

- full presence;

- $\quad$ spiritual and mutual equality;

- eye contact;

- clear expression of information;

- interaction;

- listening and hearing;

- trust the world and other people;

- connection with the surrounding world;

- responding to a dialogical situation;

- deep feeling of one's own "Me";

- high level of rational thinking;

- high level of reflection;

- autonomous individual behaviour;

- individual position and doubt of it, be able to change one's personality, be able to recognise own lack of knowledge or weakness, be able to ask for help from another person and receive it;

- equality;

- tolerance;

- fresh ideas.

Dialogue components also serve as indicators of possible barriers in a mediation process because they comprise diversity of necessary actions, ethics, norms and personal qualities, and it is quite hard work to learn and keep it. The following barriers can originate in the mediation process:

- disinterest of the theme of dialogue;

- lack of motivation to be in dialogues;

- lack of time to be in dialogues;

- individual priorities of partners;

- fear of dialogue;

- fear of information and new knowledge; 
- fear of one's lack of knowledge;

- lack of respect of the partner;

- reluctance to change one's position;

- discrepancy of values and/or intellect;

- lack of empathy;

- lack of misunderstanding a partner's non-verbal and verbal communication;

- phobias;

- failure to be able to concentrate for a dialogical process;

- various outer disturbances/conditions.

Functions of dialogue:

- promotion of mutual understanding;

- promotion of respect;

- cultural;

- co-operative;

- promotion of democracy.

Constructivism and particularly J. Mezirow's (Mezirow, 1991, 2000) transformational learning theory can be used by a mediator helping to develop clients' dialogical skills. The theories emphasize the importance of reflection and according to J. Mezirow (1991) it is an essential means how people understand themselves and others better, and new meaning schemes and transforming of meaning perspectives are implemented. That's why the usage of the mentioned theories could be a contribution in the mediator's methodological work with clients.

Psychologist and dialogue coach S. Rozenthuler (Rozenthuler, 2014; Gethin, 2016) trains leaders, teams and organisations to develop open and honest conversations. She recognizes that the open conversations promote to build trust, inspires new ideas, cultivates collaboration, resolve conflict, improve relationship, increase wellbeing, encourage creativity, create more meanings, open doors and expand flexibility. Her recognitions are from practice, and at the same time can be related to dialogical relations.

Dialogue group practices are a good example how people gradually learn more about each other in the process of dialogue. The dialogue partners learn to look into their inner selves and practice knowing themselves and partners better. Considerable example is career support where dialogue is one of the main methods of counselling (Soika, 2015,345) helping to focus the student on mutual consistency of his own ability, interest and his vocational activities.

Dialogue represents democratic relations and an opportunity to be in dialogical relations belongs to human rights. It is reflected in the Universal Declaration of Human Rights by the United Nations (United Nations, 1948) particularly in articles 1 and 19: All human beings are born free and equal in dignity and rights. They are endowed with reason and conscience and should act towards one another in a spirit of brotherhood (article 1). Everyone has the right to freedom of opinion and expression; this right includes freedom to hold opinions without interference and to seek, receive and impart information and ideas through any media and regardless of frontiers (article 19). The declaration is a very good reason and one of the basic documents for the countries joined to the United Nations. It means that dialogue should be fostered by every citizen and in every situation to come to the truth and find solution, and it is a work for the benefit of all the humanity. B.L. Mallory and N.L. Thomas remind that consciously moving away from the win-lose model of traditional debate to a more equitable, safe and sustained approach to problemsolving, we can foster both ethical principles and democratic governance (Mallory, Thomas, 2003, 2).

\section{Conclusions}

Dialogue functions, components and barriers are three groups of factors every person has to consider in the process of mediation. A mediator's task is to explain clients the essence and impact of each factor in the conflict solving process. Therefore, learning to be in dialogical relations should be organised before starting the actual dialogue with other person to solve the conflict.

Continuous development of dialogue components promotes the quality of learning and understanding of the individual's human opportunities in the frame of interpersonal relations. By means of the mediator's help in the dialogical process transformations go on with every individual because the 
dialogue is a special condition where partners try to understand each other, go deeper in the context of the conflict, investigate and solve it.

Dialogue as one of the ways of communication is effective because its added value is quite multi-sided. It is a means how people get more knowledge about each other including views, emotions and a personality in general. Both sides are winners because they overcome barriers, widen interpersonal experience, intelligentsia and their world view.

\section{Bibliography}

1. Bakhtin M. (1984). Problems of Dostoevsky's Poetics (Theory and History of Literature). In C. Emerson (Ed), 8. Minneapolis: University of Minnesota Press.

2. Bohm D. (2004). On Dialogue. London and New York: Routledge Classics.

3. Bohm D., Factor D., Garrett P. (1991). Dialogue - a Proposal. Retrieved from $\mathrm{http}$ //infed.org/archives/e-texts/bohm_dialogue.htm

4. Buber M. (2010). I and You. Mansfield, USA: Martino Publishing.

5. Freire P. (1972). Pedagogy of the Oppressed. Harmondsworth: Penguin.

6. Gethin W. (2016). Top Ten Benefits of Skilful Dialogue. Retrieved from http://www.lifeartsmedia.com/top-ten-benefits-of-skilful-dialogue

7. Habermas J. (1984). The theory of communicative action. Volume 1: Reason and the rationalization of society. Boston: Beacon Press. Retrieved from http://www.dphu.org/uploads/attachements/books/books_2795_0.pdf

8. Isaacs W. (1999). Dialogue and the Art of Thinking together: A Pioneering Aproach to Communicating in Business and in Life. New York: Bantam Doubleday Dell Publishing Group.

9. Jermolajeva J. (1997). Dialogical Approach to the Learning in Contemporary School. Summary of Doctoral Thesis. Riga: Latvijas Universitate.

10. Kabat-Zinn J. (2006). coming to Our Senses: Healing Ourselves and the World Through Mindfulness. New York: Hyperion.

11. Luman N. (1995). Chto takoe kommunikaciya? (What is communication?). Sociologicheskij zhurnal, 3, 114-125. (in Russian)

12. Mallory B.L., Thomas N.L. (2003). When the Medium is The Message: Promoting Ethical Action Through Democratic Dialogue. Journal of College and Character, 4(9), 2-9.

13. Mediation Law. (2014). Retrieved from https://likumi.lv/ta/en/id/266615-mediation-law

14. Mezirow J. (1991). Transformative Dimensions of Adult Learning. San Francisco: Jossey Bass.

15. Mezirow J. (2000). Learning as Transformation: Critical Perspectives on a Theory in Progress. San Francisco: Jossey Bass.

16. Purens V. (2012). Dialoga metodologija un teorija izzinas procesa (The Methodology and Theory of Dialogue in the Process of Cognition). The Humanities and Social Science. History of Science and Higher Education. Scientific Journal of Riga Technical University, 20, 59-63. (in Latvian)

17. Reports. (2019). World Economic Forum. Retrieved from https://www.weforum.org/reports

18. Roles and Duties of mediators. (2018). Government of Malta. Retrieved from $\mathrm{https}$ ://justice.gov.mt/en/mmc/Pages/Roles-and-Duties-of-Mediator.aspx

19. Rozenthuler S. (2014). Life Changing conversations: 7 strategies for talking about what matters most. London: Watkins Publishing.

20. Soika I. (2015). Entity of Dialogue in Career Guidance of Secondary Vocational Schools. In V. Dislere (Ed.), The Proceedings of the International Scientific Conference Rural Environment. Education. Personality, 8. Jelgava: LLU TF, 338-346. Retrieved from http://llufb.llu.lv/conference/REEP/2015/Latvia-Univ-Agricult-REEP-2015proceedings.pdf

21. Stanford Encyclopedia of Philosophy. (2006). Emanuel Levinas. Retrieved from https://plato.stanford.edu/entries/levinas/

22. United Nations. (1948). Universal Declaration of Human rights. Retrieved from http://www.un.org/en/universal-declaration-human-rights/

23. Yankelovich D. (1999). The Magic of Dialogue: Transforming Conflict into Cooperation. New York: Simon and Schuster. Retrieved from http://movies2.nytimes.com/books/first/y/yankelovich-magic.html 